\title{
Reading Speed and Comprehension: Influence of Methods Used to Improve Reading Skills and the Link between the Left Hemisphere and Enhanced Reading Capabilities
}

\author{
Eduardo Makoto Katsumata Rosales (Author), Enrolled in Computer Science ${ }^{1}$, \\ Carlos Roberto Arias Arévalo (Mentor), PhD Information Systems and Applications ${ }^{2}$, \\ ${ }^{1}$ UNITEC TGU, Honduras, makioto@unitec.edu \\ ${ }^{2}$ UNITEC TGU, Honduras, cariasa@unitec.edu
}

\begin{abstract}
We developed a software which measures reading skills on children of different levels of schooling. With a sample size of 819 students, we were able to retrieve strong evidence on how poorly have reading capabilities been developed on children from a primary level of education. Consequently, we identified two major factors that carry high influence to mastering such skills: methods for learning or improving current reading levels and modern tools used for measuring said levels. Our research will be centered in retrieved statistics and the benefit of using tools for measuring reading capabilities. We will also identify unique ways to improve reading, utilizing an approach that will force the left brain hemisphere to increase its influence towards reading procedures, whereas in most cases the left hemisphere has the lead but lacks training, or in extreme cases such as dyslexia, underperforms under specific circumstances.

Keywords - language lateralization, reading comprehension, reading measuring tools, reading skills, reading speed.
\end{abstract}

\section{INTRODUCTION}

Reading skills and a high level of literacy have become essential in terms of acquiring a decent job and improving quality of life for the 21 st century. It is logical to assume that lacking such skills will result in an enormous disadvantage in a competitiveness centered world. Unfortunately for a vast majority of citizens who reside in third world countries poor reading skills is a reality, leading to a state of poverty.

Globalization has forced many countries to try and increase levels of literacy by implementing various projects, programs and policies, which have resulted in almost unnoticeable increments, if any. These mediocre results will not vary if we keep utilizing the same methods for improving and measuring reading skills on children from different levels of schooling.

These facts are demonstrated by a field research that was executed in September of the year 2015. We utilized a software based tool that accurately measure reading speed, reading comprehension and oral comprehension. This tool surpasses other measuring methods because it isolates students into the measuring environment, focusing their full attention.

Results prove that there is a high percentage of students that show deficit in terms of reading speed or reading comprehension. This indicates that current methods used for improving reading skills are flawed or lack traits needed for a

Digital Object Identifier: (to be inserted by LACCEI). successful experience. By modifying the way students train their reading skills, improvement can be acquired.

\section{RESEARCH SAMPLE}

This research was done by using the reading and comprehension software in several public schools, under the umbrella of the project "Unidos para la Mejora de la Calidad Educativa (UMCE)", an educational project led by UNITEC Honduras. This led to a sample of 819 students from fourth to sixth grade and the measure of their reading skills. These students belonged to a total of 14 different schools.

The amount of selected students for each institute (See Table I) represent a $10 \%$ of the total population of enrolled students, randomly picked from fourth to sixth grade.

TABLE I

SELECTED INSTITUTES AND SAMPLE

\begin{tabular}{|l|c|}
\hline \multicolumn{1}{|c|}{ Educational Institute (School) } & Sample (Students) \\
\hline CEB Herman Herrera & 58 \\
\hline CEB Jaime Romero Zúniga & 38 \\
\hline CEB República de China & 24 \\
\hline CEB Tim Hans & 24 \\
\hline CEB Virgen de Suyapa & 23 \\
\hline Esc. aplicación República de Paraguay & 56 \\
\hline Esc. Esteban Mendoza & 114 \\
\hline Esc. Lisandro Quezada & 54 \\
\hline Esc. José Ramón Cálix Figueroa & 113 \\
\hline Esc. Aplicación Rep. De Uruguay & 51 \\
\hline Esc. Gustavo Simón Núñez & 77 \\
\hline Esc. guía técnica José Trinidad Reyes & 31 \\
\hline Esc. John F. Kennedy & 127 \\
\hline Esc. José Simón Azcona & 25 \\
\hline
\end{tabular}

III. READING SPEED AND COMPREHENSION SOFTWARE

Digital Object Identifier (DOI): http://dx.doi.org/10.18687/LACCEI2016.1.2.018 ISBN: 978-0-98228996-9-3

ISSN: $2414-6390$

$14^{\text {th }}$ LACCEI International Multi-Conference for Engineering, Education, and Technology: "Engineering Innovations for Global Sustainability”, 20-22 July 2016, San José, Costa Rica. 
In order to ease the difficulty of evaluating 819 students individually and in the shortest time possible, we designed a software that was capable of measuring reading speed, reading comprehension and oral comprehension. Such software reduced the time needed in order to completely evaluate a single student from an average of 20 minutes to just 4 minutes.

Groups of five people evaluated a total of 50 students per day, completing the whole procedure in just 16 days, whereas it would have taken around 80 days to fulfill such task while using traditional methods.

Since the original version of the software, which simply covered the needs claimed by the project, it has been undergoing several changes, and is now a fully functional dynamic tool. The main interface is describe as follows.

\section{A. Menu}

The menu interface (see Figure I) allows the user to add educational institutes, students and evaluations. It also provides the option to export recollected data into Excel format and save instances of every evaluation and other objects acquired throughout the process.

FIGURE I

MENU INTERFACE

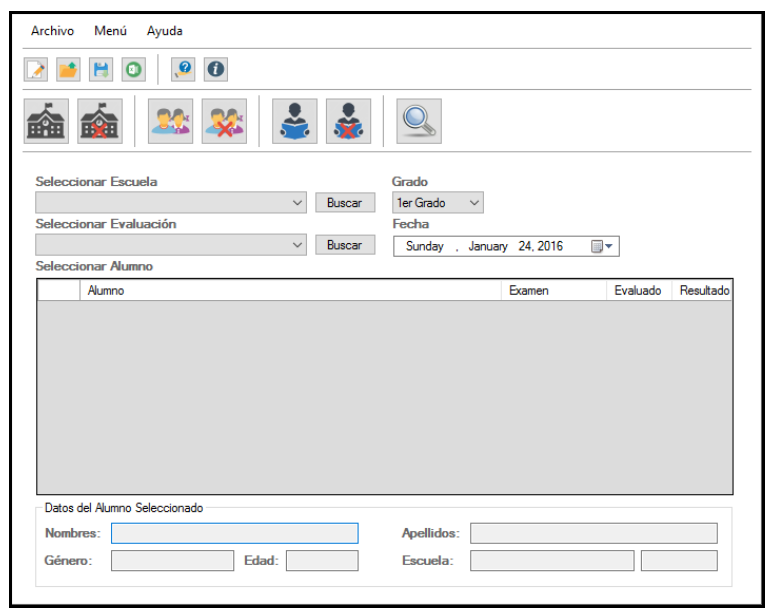

\section{B. Oral Comprehension}

The first part of the oral comprehension interface (see Figure II) must be utilized in conjunction with a pair of headphones. It narrates a text to subjected individuals, so they can process and comprehend details about said story. For every category (fourth, fifth and sixth grade) there is a different story, with different elements to evaluate.

The second part of the oral comprehension interface (see Figure III) evaluates how much of the narrated text was comprehended by the subjected individual, utilizing a series of questions and assigning a corresponding level depending on how many of those questions were answered.

FIGURE II

ORAL COMPREHENSION INTERFACE 1

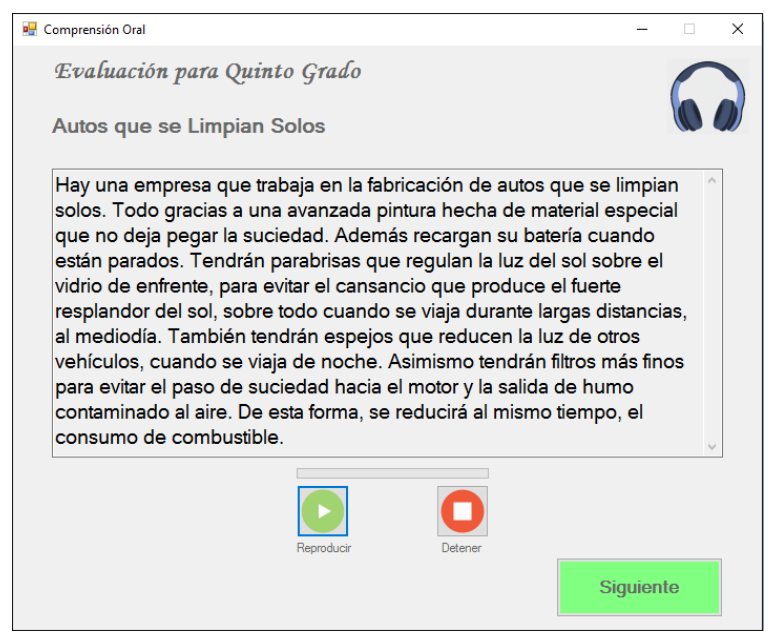

FIGURE III

ORAL COMPREHENSION INTERFACE 2

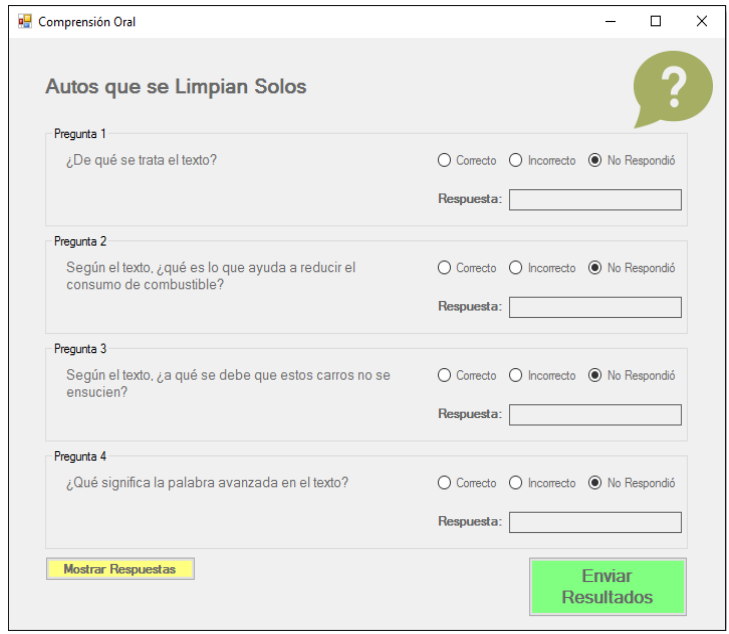

\section{Reading Speed and Reading Comprehension}

After the oral comprehension section, the reading speed and reading comprehension interface is presented (See Figure IV). While the subjected individual reads the text shown, the evaluator keeps track of misread words and the amount of time that was necessary by the user in order to read all the text. The software will then assign a corresponding level of reading speed, depending on how many words per minute was the individual capable of correctly reading. 
After the individual is subjected to the reading speed evaluation, a series of question is then conferred. The purpose is to assess how much of the read text was comprehended by the individual, and then assign a level of reading comprehension to the student.

\section{FIGURE IV}

READING SPEED AND READING COMPREHENSION INTERFACE

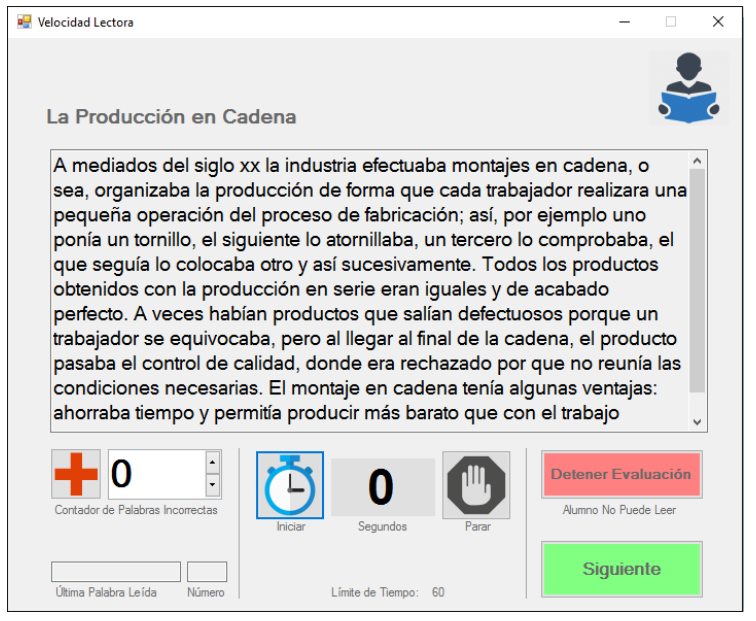

FIGURE V

READING COMPREHENSION INTERFACE

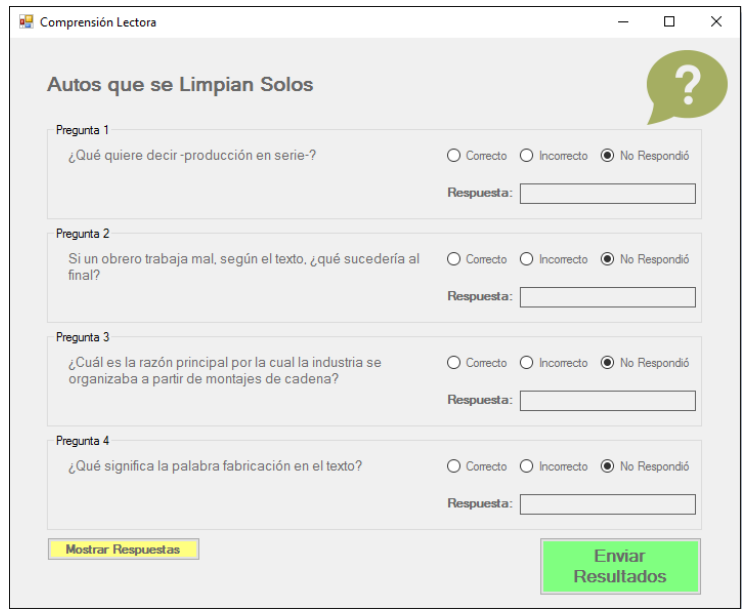

IV. RESULTS

Out of the sample of 819 students that were subjected to our tool, an impressive total of 555 students were far from close to having a standard level of reading, and another 116 students where close it. That means that only 145 students, merely $18 \%$ of the whole sample, had average reading skills for their age (see Figure VI).
FIGURE VI

SAMPLE RESULTS OF THE READING AND COMPREHENSION TEST

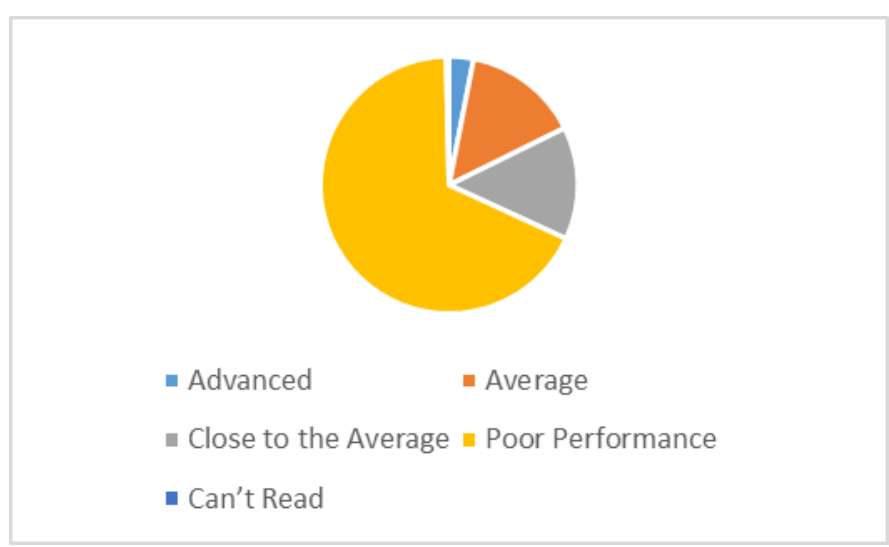

\section{NEW APPROACH}

Results shown by this research demonstrate that there exists a serious reading problem in children from fourth to sixth grade. Consequently, if there exists a problem there also exists something that is causing it. When talking in terms of reading speed, the most probable cause is the way that students are learning how to read on their early years of education. This leads to a new approach, which consists in adding a learning module to our reading speed measuring tool.

The next sections will show the background research necessary in order to implement the new proposed module into the designed software. It will explain all the terms and methods that will be used in conjunction in order to achieve far better results in children of different ages, as well as in adults and children with special needs.

\section{LANGUAGE LATERALIZATION}

Language lateralization states that the left hemisphere is the one in charge of most rational and logical functions, including reading comprehension and general abilities related to speech, whereas the right hemisphere focuses on visuo-spatial and emotional functions [2].

If we observe common reading disorders such as dyslexia, we can conclude that the main reason for such disorders to disrupt the bearers reading capabilities, is centered in the fact that their left hemisphere underperforms and leaves the reading task to the right hemisphere, causing malfunction when processing gathered information [3].

By somehow improving left hemisphere coordination with its tasks, a certain level of mastery can be achieved, in terms of reading skills. Even for people who suffer from reading disorders, improving the underperforming hemisphere will result in noticeable improvement to their reading capabilities.

\section{PRACTICE BRINGS PERFECTION}

14 ${ }^{\text {th }}$ LACCEI International Multi-Conference for Engineering, Education, and Technology: "Engineering Innovations for Global Sustainability", 20-22 July 2016, San José, Costa Rica. 
Rajkoomar certainly has a point when he said "Practice is the best way by which one can achieve perfection," [4] and we have most likely experienced a particular incident in our life where we had to practice in order to learn something. This concept can be applied to many things, including parts of the human body. The same way people lift weights in order to train their muscles, the brain can be trained to enhance functions or learn new things.

\section{TRAINING THE LEFT HEMISPHERE}

Skills such as working memory, planning, organization and attention develop over time with brain maturation and with practice [5]. Reading speed and reading comprehension can both be enhanced with constant practice and stimulation of the left hemisphere [6]. Most forms of brain stimulation are performed as physical tasks, forcing parts of the body who are controlled by a specific hemisphere to perform activities that will put its corresponding hemisphere into a state of activity.

By following the pattern that was introduced at the latter section, we can assume there exist various ways in which we can particularly train the left hemisphere in order to enhance its abilities. But are all these methods efficient? Certainly not.

There exist multiple ways in which an individual can strengthen their left side of the brain. Some of these include generic mental exercises, physical activities, and music [7]. Unfortunately, these methods will probably have almost no significant effect, in terms of reading speed and comprehension, as they focus in a more generic and noncentralized training.

By finding a method that will focus specifically on reading skills, we can safely assume that the left hemisphere will most likely become better at reading, consequently enhancing general reading comprehension and speed. This can be accomplished by forcing the left hemisphere into a state of consistent and perpetual processing, giving it a higher influence when reading already known words.

\section{ALTERING TEXT INTO "NO-WORDS"}

While it is true that both brain hemispheres have a crucial role at gathering data and information, at the moment of processing words and content, the left hemisphere takes the lead [8]. By altering what we are looking at, we can also alter how it is processed.

A person who has a dominant left hemisphere can easily express itself in words [9], and will most likely have no problem identifying different words who are disguised as symbols. A resting left hemisphere will probably work harder in order de decipher said symbols. By this logic, it can be assumed that subjecting individuals into reading texts with altered characters, called as "No-Words" (Words hidden as symbols or uncommon combinations of characters), will be actively using their left hemisphere in order to gather and process information [10].

We can abuse the latter method by making it repetitive, forcing children to read text that will never have the same combination of characters for the same word, forcing the whole process of data assimilation and processing happen all over again. Children subjected to said method will most likely have a dramatic increase of reading skills when presented with normal text formed by unaltered characters. An example of the above would be:

\section{Altered Text:

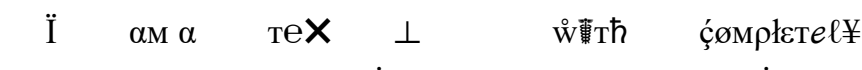

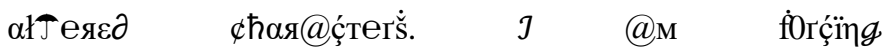

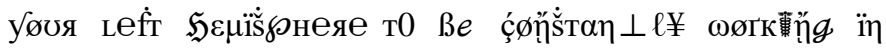

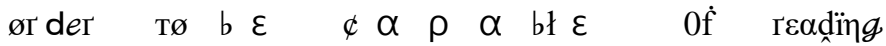

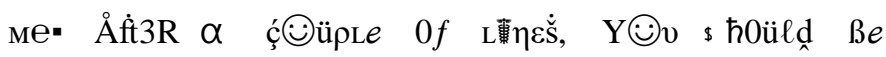

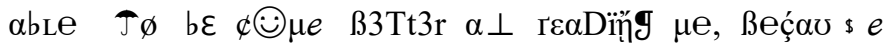

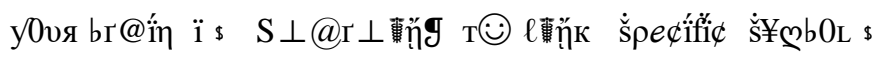

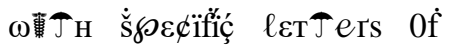 \\ $\perp \mathfrak{H} \varepsilon$ ałp $\mathfrak{H} \alpha b \mathrm{e}$ 丁. \\ Unaltered Text:}

I am a text with completely unaltered characters. I am not forcing your left hemisphere to be constantly working in order to be capable of reading me. After a couple of lines, you should be able to become better at reading me, because your brain is starting to link specific symbols with specific letters of the alphabet.

Reading the altered version of the text is a challenging task, especially for those who are unable to completely use their left hemisphere in order to read, leaving most of the work to the right hemisphere, which can't associate a pattern of letters into a specific word, because no pattern ever repeats itself. We are basically forcing the left hemisphere to do more work in order to understand what it's trying to process.

By utilizing this method we train the left hemisphere of the brain to focus specifically on understanding and figuring out what it is trying to read, performing a better task at improving reading skills compared to the current used method in most educational institutions.

\section{CONCLUSION}

The results gathered from this research suggest a strong deficit in terms of reading speed in children from fourth to sixth grade. Said deficit is most likely due to the way how children are currently learning how to read in their first years of

$14^{\text {th }}$ LACCEI International Multi-Conference for Engineering, Education, and Technology: "Engineering Innovations for Global Sustainability", 20-22 July 2016, San José, Costa Rica. 
education. This leads to a new approach that will surely benefit the way that children learn and improve their reading skills.

Understanding the way our brain works in order to improve certain skills and abilities can transform into better results. By abusing the link between the left hemisphere and reading procedures, we are capable of implementing a new method that has better benefits and results compared to the current known methods that supposedly increase reading capabilities.

Even if the research has theoretical background that supports the presented method, we will require exhaustive testing, as well as assistance from schools and different educational institutes to promote and implement it into society.

\section{REFERENCES}

[1] K. Duke, P. David, "Effective Practices for Developing Reading Comprehension," The Journal of Education, Vol. 189, No. 1/2, pp. 107$122,2009$.

[2] Language lateralization and dominance of left hemisphere http://www.oecd.org/edu/ceri/neuromyth6.htm

[3] What causes it? Reading from Scratch: Dyslexia http://www.dyslexia.org/what_causes.shtml

[4] R. Manish, "Essay on Practice Makes a Man Perfect" http://www.publishyourarticles.net/knowledge-hub/essay/an-essay-onpractice-makes-a-man-perfect/1513/

[5] S. C. Margaret, PHD, "Research in Brain Function and Learning". http://www.apa.org/education/k12/brain-function.aspx

[6] J. Robertson, J. Bakker, "The Hemispheric Balance Theory" http://www.beatingdyslexia.com/balance-theory.html

[7] Exercises to stimulate the left side of the brain, http://www.livestrong.com/article/343823-exercises-to-stimulate-the-leftside-of-the-brain/

[8] Pobric G, Mashal N, Faust M, Lavidor M "The role of the right cerebral hemisphere in processing novel metaphoric expressions" pp. 170-181, 2008

[9] Brain Hemispheres, Kidport Reference Library, http://www.kidport.com/reflib/science/HumanBody/NervousSystem/Brain Hemispheres.htm

[10]J. David Weber, "Methods and apparata for enhancing text to increase reading speed and comprehension," Patent: US 20020124026 A1, September 2002.

$14^{\text {th }}$ LACCEI International Multi-Conference for Engineering, Education, and Technology: "Engineering Innovations for Global Sustainability”, 20-22 July 2016, San José, Costa Rica. 